responsibility, in our system, is transferred. However, the growth of private medicine could bring this issue once more to the fore. Meanwhile, for doctors in the National Health Service, issues of responsibility and blame are usually resolved by health authorities well short of action by the General Medical Council or the law courts. Patients here have so far been at a considerable disadvantage when it comes to filing complaints about clinical incompetence. Now that medical authority, both technical and charismatic, is being increasingly questioned there could be a tendency towards more litigation, an outcome regarded with horror by most doctors but one which would certainly make the philosophical problems discussed in this volume of more than theoretical interest.

UNA MACLEAN

Department of Community Medicine University of Edinburgh.

\section{Expensive Medical Techniques. Report of a Working Party}

Convenor D Russell Davis. London, Council for Science and Society, 3/4 St Andrews Hill, EC4V 5BY, 1983. $\$ 5.00$ hardback, $£ 2.50$ soft cover, plus $40 \mathrm{p}$ postage

This lucid and informative report is concerned with criteria and procedures for National Health Service (NHS) priority decisions about the introduction of expensive new medical techniques (EMTs). The report discusses techniques of diagnosis, treatment and prevention, but excludes consideration of drugs: 'expensive' is not defined precisely, but is taken to mean that expenditure on the technique 'cannot be found from within an existing NHS budget and that a decision to allocate funds to it has to be made in competition with other desirable improvements or developments'. Examples given from recent decades include: screening, from mass miniature radiography to amniocentesis and computed tomography; treatment, from hip replacement surgery to dialysis and organ transplantation; and care, from special care baby units to coronary care units. Reviewing these developments the working party catalogues a variety of difficulties which have been encountered in bringing EMTs into regular use - 'the inadequacy of the evaluation beforehand, the narrowness of the criteria, the inadequ- acy of the planning of services with regard to the number and location of units, the over-use of EMTs, the neglect of non-medical alternatives, the lack of consultation with other experts and the public, and the lack of the information provided for the public and the media'. Going on to discuss current decision-making practice about the introduction of EMTs, with reference to the role of central departments, regions and districts, universities and research funding, Community Health Councils, pressure groups and the media, the working party points to defects and inadequacies (including the interesting variety of ways in which EMTs can 'turn up first as a cuckoo in an unsuspecting (health) district's nest') which go some way towards justifying the claim, made in its preface, that the report 'uncovers a most disturbing deficiency of simple rationality in the workings of one of the most important of all our social institutions'.

That the working party's main procedural remedy for this deficiency may seem as unoriginal as what it 'uncovers' is unsurprising, at least to those with some knowledge of the workings of the NHS. The remedy - at any rate the main point taken by the media at the time of the report's publication in February 1983 - is the appointment by the Secretary of State of 'an advisory group on EMTs who should be given responsibility for ensuring that EMTs are evaluated clinically'. (This recommendation is made as a suggested first step towards what the working party would really like to recommend, but consider hopelessly unrealistic in the current economic climate, namely a national institute of health service research which would do the same job more thoroughly). However, although the suggestion of yet another committee may seem hackneyed, the working party makes out a skilful case for such a body as a useful counterbalance to the haphazard, interest- and pressureprone workings of current practice. Its reference, by way of an imperfect analogy, to the Committee on Safety of Medicines, is also suggestive.

Despite the importance of this major recommendation, it would be a pity if this were seen as the report's main contribution to current debate about EMTs, since the report could also have a useful wider educational and informative function. The working party's chapter on criteria, particularly 'the information required about an EMT before a decision is taken to allocate resources to it' provides 'a checklist for the wary' which repays careful reading.
In discussing procedures, the working party has suggestions to make about the wider use of advice and consultation, involving non-medical expertise and public participation, which might help avoid some of the social and personal as well as economic costs of introducing new medical technology. In the end, no doubt, decisions made by an advisory group may be the crucial determinant of policy - not least if, as the working party admits, such vital questions as that of 'how long a new EMT should receive short-term financing before a decision is taken whether to make it generally available' are 'a matter of judgment'. But such judgment will undoubtedly be better informed if the considerations raised in the report are taken seriously. What will also matter however, is whether such considerations are seen primarily in terms of improving diagnosis, treatment and prevention, or primarily as rationalisations for costcutting as an end in itself. The working party expresses the good utilitarian belief that 'current practices can be improved without discouraging initiative or adding to the bureaucracy'. But it also admits that, when all the evaluation has been done, 'almost any development has the effect of increasing the overall demands on the service'. One can only hope that the splendid rationality of this liberal Benthamite report will not be used for less liberal ends.

KENNETH M BOYD Scottish Director Society for the Study of Medical Ethics.

\section{Consent in Medicine: Convergence and Divergence in Tradition}

Eds G R Dunstan and Mary J Seller. London, King Edward's Hospital Fund and Oxford University Press, 1983. $£ 8.50$

This useful book is the literary testament of a small but distinguished group which met, over five years, 'to study and discuss selected topics in medical science and practice in the light of the Hippocratic, Jewish and Christian traditions'. Its discussions began from a remark, made, we are told, in an underground car park, by Professor Paul Polani to Professor Gordon Dunstan, about differences between Jewish and other ethical assumptions concerning medical practice. The professors' academic curiosity was stimulated; and later, in 
less austere surroundings, discussion was joined with others including the Chief Rabbi, whose explication of some of the relevant assumptions enabled the group to focus on the major theme of this publication, namely the relative importance of consent in the three traditions mentioned.

The Chief Rabbi's comments comprise one of the six chapters of this book which are based on the group's working papers, refined through discussion. The fundamental assumption which he makes is that of the 'absolute, intrinsic and infinite value of human life'. This assumption implies that 'a patient has no right to refuse medical treatment deemed essential by competent medical opinion for the preservation of his life or health, and his consent need not be procured for such treatment'. It also justifies withholding from a patient a fatal diagnosis - or rather, to be more accurate, it makes divulging such a diagnosis something which requires justification. These implications, clearly, are not those of the ethical assumptions of all non-Jewish doctors and patients. Why this is so is suggested in a chapter by Fr Brendan Soane on consent in the Catholic tradition, which places comparatively greater emphasis on the value of autonomy, and in a further chapter by Mr Peter Byrne, who mentions the classical philosophical assumptions which entered the Christian tradition. Mr Byrne's chapter goes on to examine difficulties raised on the one hand by the absolute value of human life in Judaism and on the other by the Catholic tradition's willingness to qualify this view. Difficulties about the Jewish tradition are raised in connection with the idea that selfsacrifice in a noble cause is praiseworthy, while criticism of the Catholic tradition takes the from of a philosophical variant on the old question of 'How far can you go, Father?', although in this case with implications for suicide rather than sexuality.

Doctors and patients unfamiliar with Jewish ethical assumptions about consent might also be ignorant of the Hippocratic. In a substantial historical chapter, their needs are met by Professor Polani, who argues that 'the issue of consent was apparently not considered until recent times' and suggests some reasons why the subject is now attracting more attention in Western culture, law and medical practice. An appended note to this chapter by $\mathrm{Mr}$ Ian Kennedy takes issue with Professor Polani's conclusions, at least as far as the law is concerned, and goes on to make some useful suggestions concerning the law, consent and minors. This last subject is also discussed in Fr Soane's contribution and in the book's final chapter, by Dr Eliot Philipp and Dr Stewart Johnson, which reviews consent in relation to various aspects of medical practice.

These summary comments fail to do justice to what is a most lucid, readable and informative book, and also to the careful arguments, particularly of Professor Dunstan, the Chief Rabbi, Mr Byrne and Fr Soane. Inevitably there are loose ends. In his introductory chapter, which attempts to draw together some threads of the discussion and give a pattern to the questions it raised, Professor Dunstan makes out a helpful case for use of the term 'covenant' rather than the narrower 'contract' in talking about the doctorpatient relationship within which issues of consent commonly arise. This suggestion receives some support in Professor Polani's chapter, but is somewhat dented when one of the authors of the final chapter records that, in reply to his enquiries, the Medical Defence Union stated, 'we do not think the word "covenant" would be at all appropriate in the context of relations between doctor and patient'. Such a magisterial response from the Hippocratic tradition may simply reflect difficulties arising from certain legal uses of the word, as Professor Dunstan suggests, or it may reflect a broader English philosophical conservatism: one's impression is that the term has proved less unacceptable within the more open texture of transatlantic thought. On the other hand this particular loose end also suggests what seems most obviously lacking from this book, namely the 'overheard conversations' themselves, to use the phrase with which the introductory chapter tantalises the reader. Professor Dunstan ends that chapter by stating that 'there is still room for men of strong convictions, differing convictions, calmly and in amity to exchange ideas'. Greater evidence of the actual 'exchange' would certainly have been interesting. As it is, the exchange with which we are presented is rather more like that of diplomatic notes. But admittedly, they are notes for the most part of good quality and make stimulating reading, for which we should be grateful.

KENNETH M BOYD Scottish Director Society for the Study of Medical Ethics.

\section{Who Should Decide? Paternalism in Health Care}

James F Childress. New York, Oxford University Press, 1982. £20.00年 hardback.

People vary. Every reasonably sensitive and understanding doctor soon discovers that some patients want to hear about risks and options and also totake part in difficult decisions - so far as this is possible for the untrained and $\overrightarrow{-}$ inexperienced person. But he also sees that others (no matter how intelligent and regardless of what they may haved said before they became ill and frightened) long for firm, reassuring professional decisions - which thexir hope will be based on a mixture of skilP and kindness and taken on their behalf with a minimum of discussion. This has surely always been the ethic of traditional orthodox medicine, though we may not always have lived up to it. $\overline{\widehat{O}}$

So why has 'paternalism' recently? become almost a dirty word among $\overrightarrow{0}$ some doctor watchers? Partly, it seems $\stackrel{\infty}{\infty}$ because we are less trusted than we ueㅠ영 to be to make sensible decisions - ân partly because of a general lack awareness of how 'full disclosure of relevant facts' - which sounds fine in theory - often turns out to be callous in practice. The idea that some patients must suffer, if necessary, in order tha the principle of autonomy (rather than paternalism) may remain inviolate is as unattractive to most caring doctors as it. is to most distressed friends ants relatives. Moreover, a direct question tọD the patient as to how much information he wants - though sometimes helpful 3 often merely serves to sow hurtful seed of doubt, fear and conflict and to engender a feeling of inadequacy.

So what's to be done? How much? help can a practising doctor expect from a painstaking philosophical analysis=. such as this one by James Childress $N$ Professor of Religious Studies and Medical Education at the University of Virginia and 'a well knowriv contemporary ethicist'? Probably not asomuch as from a good pragmatic doctor who has learned when to speak and when to keep silent; who has profited? from his mistakes; and who fully appreciates the extraordinary subtleties and paradoxes of how different patients react - often ambivalently - unde? different circumstances. Nevertheless $\mathbb{Q}$ the book is highly recommended for itsooverall balance, thorough scholarship 